\title{
A WATER-SOLUBLE POLYCARBOBETAINE FOR SUSTAINABLE COPPER RECOVERY
}

\author{
JULIA MOUTON ${ }^{* 1,2}$, MIREILLE TURMINE ${ }^{1}$, HÉLÈNE VAN DEN BERGHE $^{3}, \&$ JEAN COUDANE $^{3}$ \\ ${ }^{1}$ Sorbonne Universités, UPMC Univ Paris 06, CNRS, UMR 8235, France \\ ${ }^{2}$ EPF-Graduate School of Engineering, France \\ ${ }^{3}$ CNRS - UMR 5247 - Université Montpellier, Faculté de Pharmacie, France
}

\begin{abstract}
This study targets betaine-type polymers (polycarbobetaines - PCBets) as complexing agent of metal ions. As PCBets are pH-sensitive, the adsorption isotherms of copper onto PCBet were monitored at various $\mathrm{pH}$ (from 3 to 6) by electrochemical measurements. The best fit to the Langmuir model translates the predominantly homogeneous distribution of the chelating groups on the polymer chains because the Langmuir equation assumes that the adsorbent surface is energetically homogeneous. The results obtained for the complexation of copper were greatly enhanced as the $\mathrm{pH}$ increase and reached $250 \pm 10 \mathrm{mg} \mathrm{g}^{-1}$ at $\mathrm{pH}=6$. Such maximal adsorption capacities compete with recent results obtained for molecules of environmental interest such as chitosan, for example. The copper adsorption efficiency was shown stable for soft to hard water. The selectivity of the target PCBets for copper was indicated in the presence of nickel, cobalt, manganese, zinc, calcium or magnesium and partially accounts for the interest in this material and demonstrated the relevance of using PCBet in environmental applications such as copper recovery. The reusability of PCBet was explored by $\mathrm{pH}$ adjustment. The results confirm that the efficiency of copper adsorption was maintained over five cycles of PCBet reuse $(99 \pm$ $3 \%$ ). A full process for copper recovery was then designed at laboratory scale for copper recovery from synthetic wastewaters.
\end{abstract}

Keywords: copper, polycarbobetaine, recovery, reuse selective.

\section{INTRODUCTION}

Currently, metals are highly studied in environmental management because of their depletion as resources and because of the increasingly common cases of pollution [1]. Thus, their recovery and valorization are key themes of recent scientific studies concerning the environment. Copper ions are produced as waste in various chemical industries, such as smelting, mining, printed circuit board manufacturing, electroplating, wire drawing, copper polishing, and paint manufacturing [2]. Various techniques, such as chemical precipitation, coagulation, solvent extraction, ultra-filtration, biological systems, electrolytic processes, reverse osmosis, oxidation with ozone/hydrogen peroxide, membrane filtration, ion exchange, photocatalytic degradation and adsorption, have been developed for the removal of metal contaminants from waste [3]. Among these techniques, precipitation appears as the most attractive, primarily because of its economical operation.

This research is devoted to the study of polybetaines as metal ion precipitating agents. Polybetaines are specific polyampholytes that possess anionic and cationic groups on the same monomer unit. Among polybetaines, polysulfobetaines, polycarbobetaines and polyphosphobetaines are prominent [4]. This study investigates polycarbobetaines (PCBets) and their interactions with copper to design chemical processes for copper valorization. 
The interactions of water-soluble polymers with metal ions are treated as surface phenomena as previously reported [5]. The most appropriate method for assessing sorption capacity is the derivation of a whole sorption isotherm [6]. Over the years, a wide variety of equilibrium isotherm models (Langmuir, Freundlich, Brunauer-Emmett-Teller, Redlich-Peterson, Dubinin-Radushkevich, Temkin, Toth, Koble-Corrigan, Sips, Khan, Hill, Flory-Huggins and Radke-Prausnitz isotherm), have been formulated [7].

\section{MATERIALS AND METHODS}

\subsection{Polycarbobetaine synthesis}

The monomer was obtained by dropwise addition of ammonium hydroxide $30 \%$ aqueous solution $(11 \mathrm{~mL})$ to acetoacetic ester $(10 \mathrm{~mL})$ under magnetic stirring for 3 hours. The solution was then left overnight to decant (12 hours), and the organic phase containing the key product ethyl3 -aminocrotonate (EAC) was collected. The yield of the monomer was $98 \%$, and its purity was checked by FTIR. The linear water-soluble polycarbobetaine namely polycarboxyethyl-3-aminocrotonate (PCEAC) was synthesized by radical polymerization, as previously reported [8, 9], by mixing EAC, acrylic acid and the initiator 2,2'azobisisobutyronitrile (5 minutes). The polymer (PCEAC) obtained in bulk was washed with an abundant amount of acetone and oven-dried at $70^{\circ} \mathrm{C}$ (approximately 55\% yield). Its chemical structure is presented in Fig. 1.

FTIR spectra were recorded using a Perkin-Elmer Spectrum 100 FTIR spectrometer using the attenuated-total-reflectance (ATR) method.

The main functional groups were identified by FTIR spectroscopy for PCEAC, including the $\mathrm{O}-\mathrm{H}$ stretching vibration at $3,192 \mathrm{~cm}^{-1} ; \mathrm{C}-\mathrm{H}$ stretching vibration at $2,939 \mathrm{~cm}^{-1}$; and $\mathrm{C}=$ O stretching vibration at $1,701 \mathrm{~cm}^{-1}$, as previously reported for a similar structure $[10,11]$. The results presented in Table 1 compare the characteristic bands between PCEAC and PCEAC/Cu complex obtained in this study and in previous work [12]. No carboxylate asymmetric stretching vibrations were recorded for PCEAC, while a symmetric vibration appeared at $1,407 \mathrm{~cm}^{-1}$. This tendency changes in the case of the PCEAC/Cu complex, with the appearance of a medium asymmetric stretching vibration at $1,608 \mathrm{~cm}^{-1}$, which is characteristic of copper carboxylates [13]. The difference between these two well-known characteristic bands in the PCEAC/Cu complex $\left(201 \mathrm{~cm}^{-1}\right)$ indicated that the coordination of the carboxylate groups occurred in a bridged form [14].

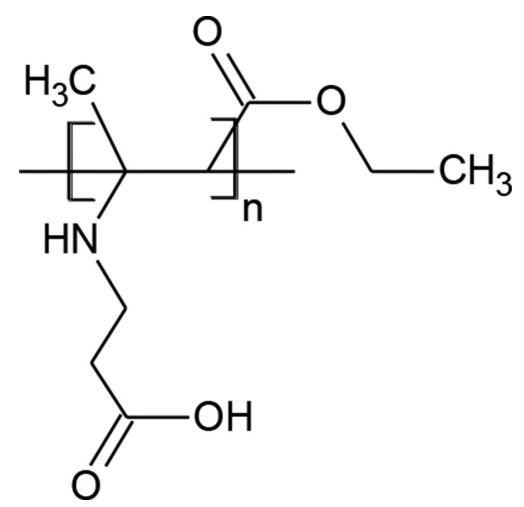

Figure 1: Chemical structure of PCEAC. 
1H-NMR spectra were recorded using a Bruker spectrometer (AMX300) operating at 300 MHz. Deuterium oxide $\left(\mathrm{D}_{2} \mathrm{O}\right)$ was used as the solvent. The chemical shifts are expressed in ppm with respect to tetramethylsilane (TMS). $\mathrm{CH}_{2}$ and $\mathrm{CH}_{3}$ groups of the ethyl function were clearly identified by the presence of a quadruplet at $3.97 \mathrm{ppm}$ and a triplet at $1.03 \mathrm{ppm}$, respectively, in ${ }^{1} \mathrm{H}$ NMR spectra of pure PCEAC. The other hydrogen atoms were observed over the expected range (from 1.43 to $2.54 \mathrm{ppm}$ ). No comparison could be performed with the ${ }^{1} \mathrm{H}$ NMR spectra of PCEAC/Cu complexes due to their insolubility in $\mathrm{D}_{2} \mathrm{O}$.

The UV-vis spectra of the polymer solutions were recorded on a Hitachi U4001 spectrophotometer with a scan range of $220-900 \mathrm{~nm}$. The aqueous solution of PCEAC $0.5 \mathrm{~g} \mathrm{~L}^{-1}(\mathrm{I}=$ $0.3 \mathrm{~mol} \mathrm{~L}^{-1}$ at $\mathrm{pH}=5$ ) exhibits an absorbance peak approximately $280 \mathrm{~nm}$, which is specific to carboxylic groups (Fig. 2), while the copper solution absorbs at $816 \mathrm{~nm}$. Figure 2 shows that the absorption for the PCEAC/Cu complex shifted from $816 \mathrm{~nm}$ to $702 \mathrm{~nm}$ and indicated the coordination interactions between the species. This band is characteristic of squarepyramidal copper(II) complexes [13]. In addition, the specific peak of PCEAC at $280 \mathrm{~nm}$ was markedly increased in the presence of copper (from 0.72 to 1.15 ), confirming the interaction between copper and polycarbobetaine carboxylate groups. This band is assigned to the carboxylate-to-copper charge transfer (ligand-to-metal charge transfer) [14].

Table 1: IR spectra of PCEAC and PCEAC/Cu complexes.

\begin{tabular}{lllll}
\hline & \multicolumn{2}{c}{ PCEAC } & \multicolumn{2}{c}{ PCEAC/Cu } \\
\cline { 2 - 5 } Bands & {$[12]$} & This study & {$[12]$} & This study \\
\hline $\mathrm{vC}=\mathrm{O}$ & 1,707 & 1,702 & 1,701 & 1,702 \\
$v_{\mathrm{as}} \mathrm{COO}-$ & - & - & 1,619 & 1,608 \\
$\mathrm{dN}-\mathrm{H}$ & 1,559 & 1,547 & - & 1,548 \\
$v_{\mathrm{s}} \mathrm{COO}-$ & 1,401 & 1,407 & 1,401 & 1,407 \\
\hline
\end{tabular}

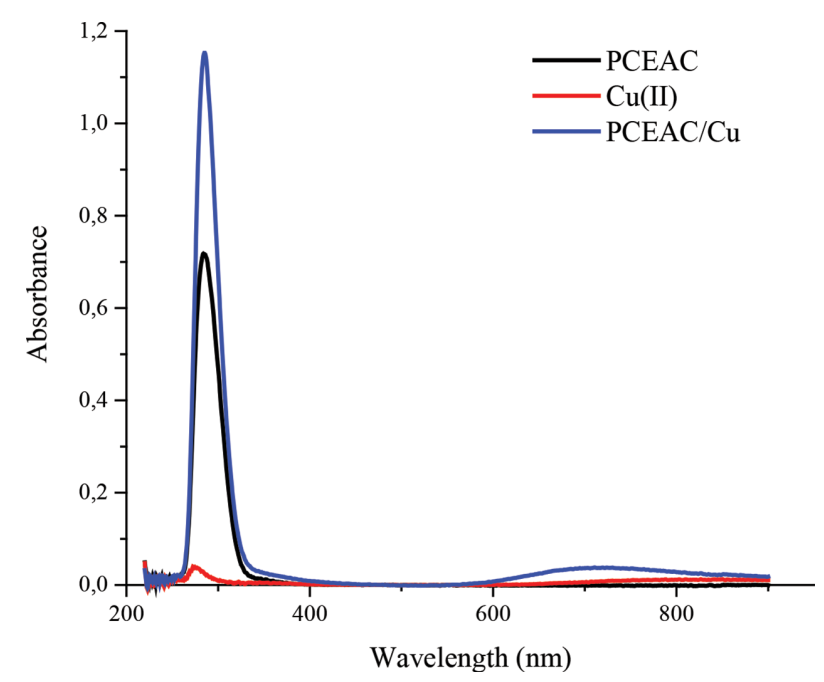

Figure 2: UV-visible spectra of PCEAC (0.5 $\left.\mathrm{g} \mathrm{L}^{-1}\right), \mathrm{Cu}$ (II) $\left(0.0005 \mathrm{~mol} \mathrm{~L}^{-1}\right)$ and/or Co(II) $\left(0.025 \mathrm{~mol} \mathrm{~L}^{-1}\right)$ in $0.1 \mathrm{~mol} \mathrm{~L}^{-1} \mathrm{Na}_{2} \mathrm{SO}_{4}$ at $\mathrm{pH}=5$. 


\subsection{Sorption experiments}

The sorption experiments were performed by the batch method $(10 \mathrm{~mL})$ in a thermostated cell $\left(25^{\circ} \mathrm{C}\right)$ with constant stirring, using PCEAC $0.5 \mathrm{~g} \mathrm{~L}^{-1}$. The adsorption behavior of the copper ions $(\mathrm{Cu}(\mathrm{II}))$ was assayed over a range from $5.10^{-5}$ to $510^{-3} \mathrm{~mol} \mathrm{~L}^{-1}$ and over a $\mathrm{pH}$ range from 3.5 to 5.5. The ionic strength (I) was fixed at $0.3 \mathrm{~mol} \mathrm{~L}^{-1}$ with sodium sulfate $\left(\mathrm{Na}_{2} \mathrm{SO}_{4}\right) 0.1 \mathrm{~mol} \mathrm{~L}^{-1}$. The $\mathrm{pH}$ was adjusted with sulfuric acid $\left(\mathrm{H}_{2} \mathrm{SO}_{4}\right)$ or sodium hydroxide $(\mathrm{NaOH})$. Adsorption isotherms were determined by monitoring free copper decay in the solution and were fitted to the Langmuir, Freundlich, Temkin, Dubinin-Radushkevich two parameters models, and to the Redlich-Peterson, Sips and Toth three parameters models. All the equations are given in Table 2.

The amount of copper adsorbed $\left(\mathrm{mg} \mathrm{g}^{-1}\right)$ at equilibrium $(\mathrm{Qe})$, defined as the soluble and precipitated fractions of PCEAC/Cu complex, was calculated from the mass balance of initial and final copper concentrations as previously reported [15].

Some of the assays were used to test the selectivity of PCEAC toward copper, cobalt $\left(\mathrm{Co}^{2+}\right)$, and nickel $\left(\mathrm{Ni}^{2+}\right)$ using electrochemical measurements and UV-visible spectroscopy. All of the experiments were conducted in triplicate under identical conditions.

Table 2: Equations and parameters used to model the adsorption isotherms of copper on PCEAC.

\begin{tabular}{|c|c|c|}
\hline Name & Equation & Parameters \\
\hline Langmuir & $Q e=\frac{Q_{m} K_{L} C_{e}}{1+K_{L} \times C_{e}}$ & $\begin{array}{l}\mathrm{Qm}=\text { Maximum monolayer adsorption } \\
\text { capacity }\left(\mathrm{mg} \mathrm{g}^{-1}\right) \\
\mathrm{K}_{\mathrm{L}}=\text { Langmuir isotherm constant }\left(\mathrm{L} \mathrm{mg}^{-1}\right)\end{array}$ \\
\hline Freunlich & $Q e=K_{f} C_{e}^{1 / n}$ & $\begin{array}{l}\mathrm{K}_{\mathrm{f}}=\text { Freundlich isotherm constant }\left(\mathrm{mg} \mathrm{g}^{-1}\right. \\
\left.\left.(\mathrm{L} \mathrm{mg})^{-1}\right)^{1 / \mathrm{n}}\right) \\
\mathrm{n}=\text { adsorption intensity }\end{array}$ \\
\hline Sips & $Q e=\frac{K_{S} C_{e}^{\beta_{s}}}{1+a_{s} C_{e}^{\beta s}}$ & $\begin{array}{l}\mathrm{K}_{\mathrm{S}}=\text { Isotherm constant }\left(\mathrm{L} \mathrm{g}^{-1}\right) \\
\beta_{\mathrm{S}}=\text { Isotherm exponent } \\
\mathrm{a}_{\mathrm{S}}=\text { Isotherm constant }\left(\mathrm{L} \mathrm{mg}^{-1}\right)\end{array}$ \\
\hline $\begin{array}{l}\text { Dubinin- } \\
\text { Radushkevich }\end{array}$ & $Q e=Q_{s} \exp \left[-K_{D R} \varepsilon^{2}\right]$ & $\begin{array}{l}\mathrm{Q}_{\mathrm{S}}=\text { Maximum adsorption capacity }\left(\mathrm{mg} \mathrm{g}^{-1}\right) \\
\mathrm{K}_{\mathrm{DR}}=\text { Isotherm constant }\left(\mathrm{mol}^{2} \mathrm{~kJ}^{-2}\right)\end{array}$ \\
\hline Temkin & $Q e=\frac{R T}{b_{T}} \times \ln A_{T} C_{e}$ & $\begin{array}{l}\mathrm{b}_{\mathrm{T}}=\text { Isotherm constant } \\
\mathrm{A}_{\mathrm{T}}=\text { Isotherm equilibrium binding constant } \\
\left(\mathrm{L}^{-1}\right)\end{array}$ \\
\hline $\begin{array}{l}\text { Redlich- } \\
\text { Peterson }\end{array}$ & $Q e=\frac{K_{R} C_{e}}{1+a_{R} C_{e}^{b r}}$ & $\begin{array}{l}\mathrm{K}_{\mathrm{R}}=\text { Isotherm constant }\left(\mathrm{L} \mathrm{g}^{-1}\right) \\
\mathrm{a}_{\mathrm{R}}=\text { Isotherm constant }\left(\mathrm{mg}^{-1}\right) \\
\mathrm{br}=\text { Isotherm exponent }\end{array}$ \\
\hline Toth & $Q e=\frac{K_{T} C_{e}}{\left(a_{T}+C_{e}\right)^{1 / t}}$ & $\begin{array}{l}\mathrm{K}_{\mathrm{T}}=\text { Isotherm constant }\left(\mathrm{mg} \mathrm{g}^{-1}\right) \\
\mathrm{a}_{\mathrm{T}}=\text { Isoterm constant }\left(\mathrm{L} \mathrm{mg}^{-1}\right) \\
\mathrm{t}=\text { Isotherm constant }\end{array}$ \\
\hline
\end{tabular}


Adsorption isotherms were determined by using non-linear regression analysis. The error function employed to evaluate the fit was the second order corrected Akaike information criterion $\left(\mathrm{AIC}_{\mathrm{C}}\right)$ defined as follows $[16,17]$ :

$$
\begin{aligned}
& A I C=N \times \operatorname{Ln}\left(\frac{R S S}{N}\right)+2 P \\
& A I C_{C}=A I C+\frac{2 P \times(P+1)}{N-P-1}
\end{aligned}
$$

where $\mathrm{P}$ is the number of parameters in the model $(\mathrm{P}=2$ or 3$), \mathrm{N}$ is the number of data points and RSS the residual squares sum.

AICc considers the size of the calibration data set and is therefore preferred over the original AIC [18].

\subsection{Sorption/desorption experiments}

Sorption/desorption experiments were performed over five cycles by $\mathrm{pH}$ adjustments. A solution of copper $0.005 \mathrm{~mol} \mathrm{~L}^{-1}$ and PCEAC $0.5 \mathrm{~g} \mathrm{~L}^{-1}$ was prepared in $\mathrm{Na}_{2} \mathrm{SO}_{4} 0.1 \mathrm{~mol} \mathrm{~L}^{-1}$ at $\mathrm{pH}=5$ (the final $\mathrm{pH}$ was 4.5 ). Desorption experiments were performed by decreasing the $\mathrm{pH}$ to 2 , and the next adsorption cycle was obtained by $\mathrm{pH}$ adjustment back to 4.5 . The $\mathrm{pH}$ was adjusted with $\mathrm{H}_{2} \mathrm{SO}_{4}$ or $\mathrm{NaOH}$. This operation was conducted four more times. The free copper in solution was followed by copper selective electrode (CSE) and the concentration was corrected considering the volume increase due to $\mathrm{H}_{2} \mathrm{SO}_{4}$ or $\mathrm{NaOH}$ addition. All of the experiments were conducted in triplicate under identical conditions.

\subsection{Copper recovery by electrodeposition}

The electrodeposition of copper was operated in a beaker with a glassy carbon electrode of $0.3 \mathrm{~cm}$ diameter (homemade) as working electrode, platinum grid (homemade) as counter electrode, and a mercurous sulfate reference electrode (Radiometer REF621). The reduction potential of copper was estimated at $-0.75 \mathrm{~V}$ by cyclic voltammetry in the following conditions: $\mathrm{Na}_{2} \mathrm{SO}_{4} 0.1 \mathrm{~mol} \mathrm{~L}^{-1}$ at $\mathrm{pH}=2$.

A $100 \mathrm{~mL}$ solution of PCEAC $0.5 \mathrm{~g} \mathrm{~L}^{-1}$ was prepared with copper $0.005 \mathrm{~mol} \mathrm{~L}^{-1}$ in $\mathrm{Na}_{2} \mathrm{SO}_{4}$ $0.1 \mathrm{~mol} \mathrm{~L}^{-1}$ at $\mathrm{pH}=5$. The precipitate was then collected after centrifugation (3000 rpm 10 minutes), and introduced in $50 \mathrm{~mL} \mathrm{Na}_{2} \mathrm{SO}_{4} 0.1 \mathrm{~mol} \mathrm{~L}^{-1}$ at $\mathrm{pH}=2$ for copper desorption. The potential was fixed at $-0.8 \mathrm{~V}$ and the electrodeposition was followed until the total deposition of copper.

\subsection{Analytical method}

Free copper in the solutions was followed on a PHM250 ion analyzer equipped with a CSE (Radiometer-ISE25Cu) and a mercurous sulfate reference electrode (Radiometer REF621). The characteristics of the electrochemical method were previously published [15]. The $\mathrm{pH}$ was also recorded using a PHM250 ion analyzer equipped with a glass electrode (Radiometer pHG301) and the same mercurous sulfate reference electrode. 


\section{RESULTS AND DISCUSSION}

\subsection{Copper adsorption onto PCEAC}

The mechanisms of copper uptake by PCEAC at pH 3.5, 4.5 and 5.5, were explored by analyzing the results of the adsorption isotherms (the experimental and predicted isotherms are presented in Fig. 3).

The amounts of copper adsorbed at equilibrium (Qe) were low at $\mathrm{pH} 3.5$. Thus, it was difficult to consider this $\mathrm{pH}$ condition to determine the best model to describe the complexation of copper. With AICc difference ( $\triangle \mathrm{AICc}$ ) between the models less than 14, it does not provide any evidence favoring one model to another [19]. As shown in Table 3, $\mathrm{AICc}$ of the Freundlich Dubinin-Radushkevich, Temkin or Toth models and the Langmuir model were greater than 14 (for $\mathrm{pH}=4.5$ and $\mathrm{pH}=5.5$ ), providing strong evidence favoring the Langmuir model as the best to describe the interaction between copper and PCEAC. Considering the Sips, Redlich-Perterson and Langmuir model, $\triangle \mathrm{AICc}$ do not provide any evidence favoring one model to another $(\Delta \mathrm{AICc}<11)$. This is probably due to the fact that the Sips and the Redlich-Peterson models are hybrid models featuring both Langmuir and Freundlich isotherms. As seen from Table 4 the values of $\beta$ s (or br) are close to 1 suggesting that the Sips and Redlich-Perterson models are reduced to Langmuir [20]. This explained the very low $\triangle \mathrm{AICc}$ between these three models and finally the Langmuir isotherm appeared as the best to describe the adsorption of copper onto PCEAC. The best fit to the Langmuir model translates the predominantly homogeneous distribution of the chelating groups on the polymer chains because the Langmuir equation assumes that the adsorbent surface is energetically homogeneous.

The maximum adsorption capacity (Qm) was substantially increased (from 51.3 to $226 \mathrm{mg}$ $\mathrm{g}^{-1}$ ) as the $\mathrm{pH}$ increased (from 3.5 to 5.5) and appeared linearly correlated to this parameter $\left(\mathrm{R}^{2}=0.9804\right)$. By comparing our results to the maximum adsorption capacities of various natural and synthetic materials recently studied for copper recovery from waste or wastewater [15], PCEAC clearly appears as a promising agent for these applications.

\subsection{PCEAC selectivity to copper}

The influence of nickel (Ni(II)), cobalt (Co(II)), manganese, zinc, calcium (Ca(II)) and magnesium $(\mathrm{Mg}(\mathrm{II}))$ on copper adsorption was investigated by electrochemical measurements (Fig. 2). Copper solutions at $5.10^{-4} \mathrm{~mol} \mathrm{~L}^{-1}\left(-215.6<\mathrm{E}_{\mathrm{Cu}}<-216.3 \mathrm{mV}\right)$ were prepared in $0.1 \mathrm{~mol} \mathrm{~L}^{-1} \mathrm{Na}_{2} \mathrm{SO}_{4}$ at $\mathrm{pH}=5$ with several different concentrations of metallic ions. Under these conditions, regardless of the metal and the ratio $(\mathrm{R})$ used, the potential of the electrode remained unchanged (with values between -215.6 and $-218.6 \mathrm{mV}$ ). The results are presented in Fig. 4 for $\mathrm{Co}(\mathrm{II}), \mathrm{Ni}(\mathrm{II}), \mathrm{Ca}(\mathrm{II}), \mathrm{Mg}(\mathrm{II})$.

The potential was kept constant (ranging from -235.2 to $-239.1 \mathrm{mV}$ ) with the addition of PCEAC $\left(0.5 \mathrm{~g} \mathrm{~L}^{-1}\right)$ to the same solutions, suggesting that $\mathrm{Co}(\mathrm{II}), \mathrm{Ni}$ (II) or others were not competing for copper adsorption. The selectivity of PCEAC toward copper was confirmed for $\mathrm{R}=50$ with cobalt by UV-visible analyses (Cf. Fig. 2). The spectra of PCEAC/Cu and PCEAC/Cu/Co were equivalent regarding the wavelength absorption maximum and the absorbance. In addition to these results, no desorption of copper occurred in favor of nickel, manganese, zinc, calcium, magnesium $(0<\mathrm{R}<10)$ or cobalt complexation $(0<\mathrm{R}<50)$. This observation agreed with previous results about the selective complexation of copper by other polycarbobetaines [15]. 

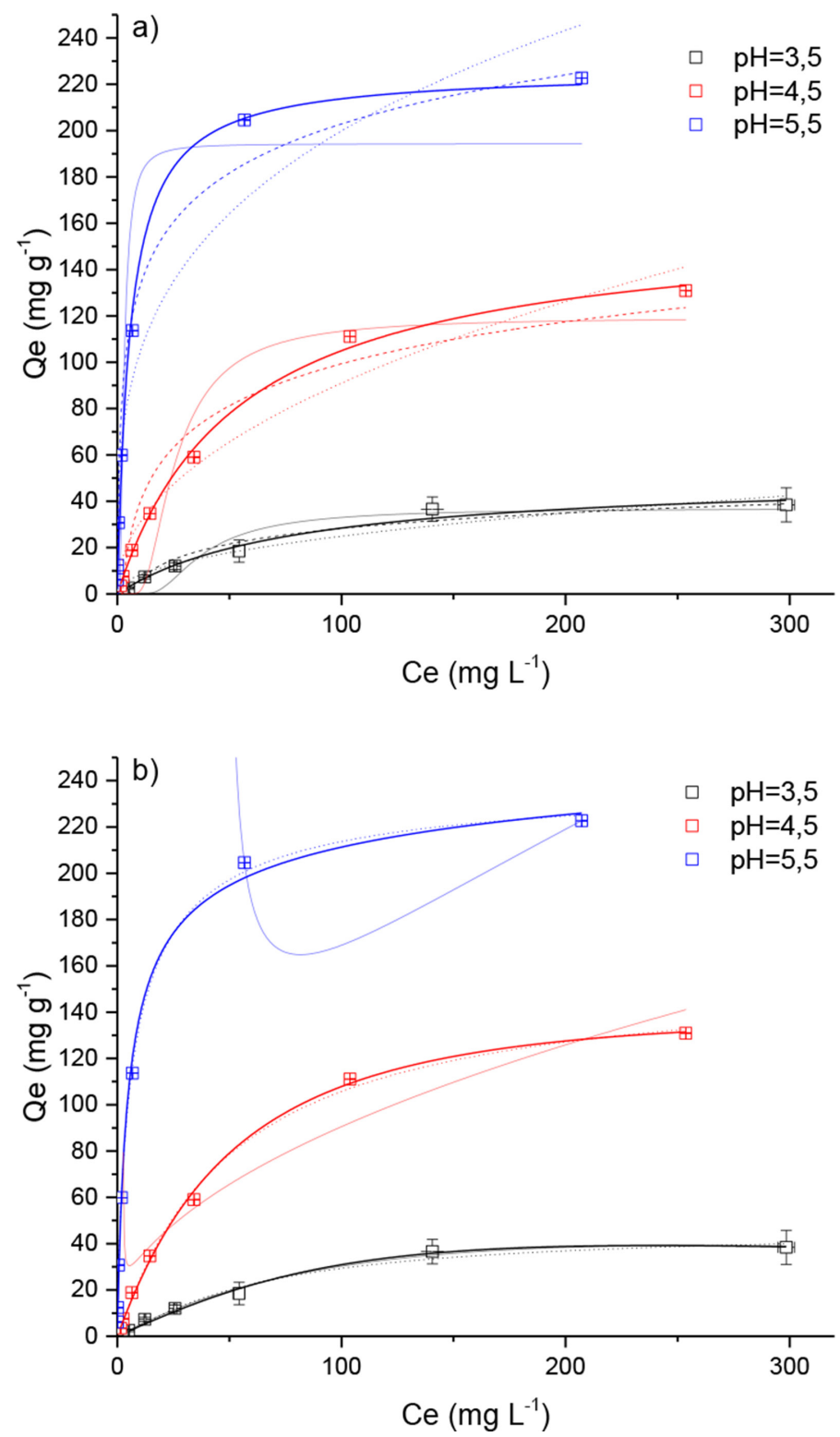

Figure 3: Adsorption isotherms of copper onto PCEAC at various $\mathrm{pH}$ values. Experimental data fitted to a) the Langmuir model (dark solid line), the Freundlich model (dot line), the Temkin model (dashed line) and the Dubinin-Raduskevich model (light solid line); b) the Redlich-Peterson model (dark solid line), the Sips model (dot line) and the Toth model (light solid line). 
Table 3: Determination of the best fitting model by comparing $\Delta$ AICc.

\begin{tabular}{lccc}
\hline $\mathrm{pH}$ & 3.5 & 4.5 & 5.5 \\
Best model & Langmuir & Langmuir & Sips \\
\hline Langmuir & 0.0 & 0.0 & 6.1 \\
Freundlich & 7.1 & $\mathbf{1 8 . 8}$ & $\mathbf{2 2 . 8}$ \\
DR & 10.2 & $\mathbf{2 4 . 3}$ & $\mathbf{2 6 . 1}$ \\
Temkin & 5.3 & $\mathbf{2 0 . 3}$ & $\mathbf{1 5 . 9}$ \\
Sips & 9.2 & 6.6 & 0.0 \\
Toth & 4.6 & $\mathbf{2 6 . 3}$ & $\mathbf{4 1 . 7}$ \\
Redlich-Peterson & 4.8 & 4.3 & 9.9 \\
\hline
\end{tabular}

Table 4: Isotherm model parameters for $\mathrm{Cu}(\mathrm{II})$ adsorption on PCEAC at different $\mathrm{pH}$ values (Langmuir, Sips and Redlich-Peterson models).

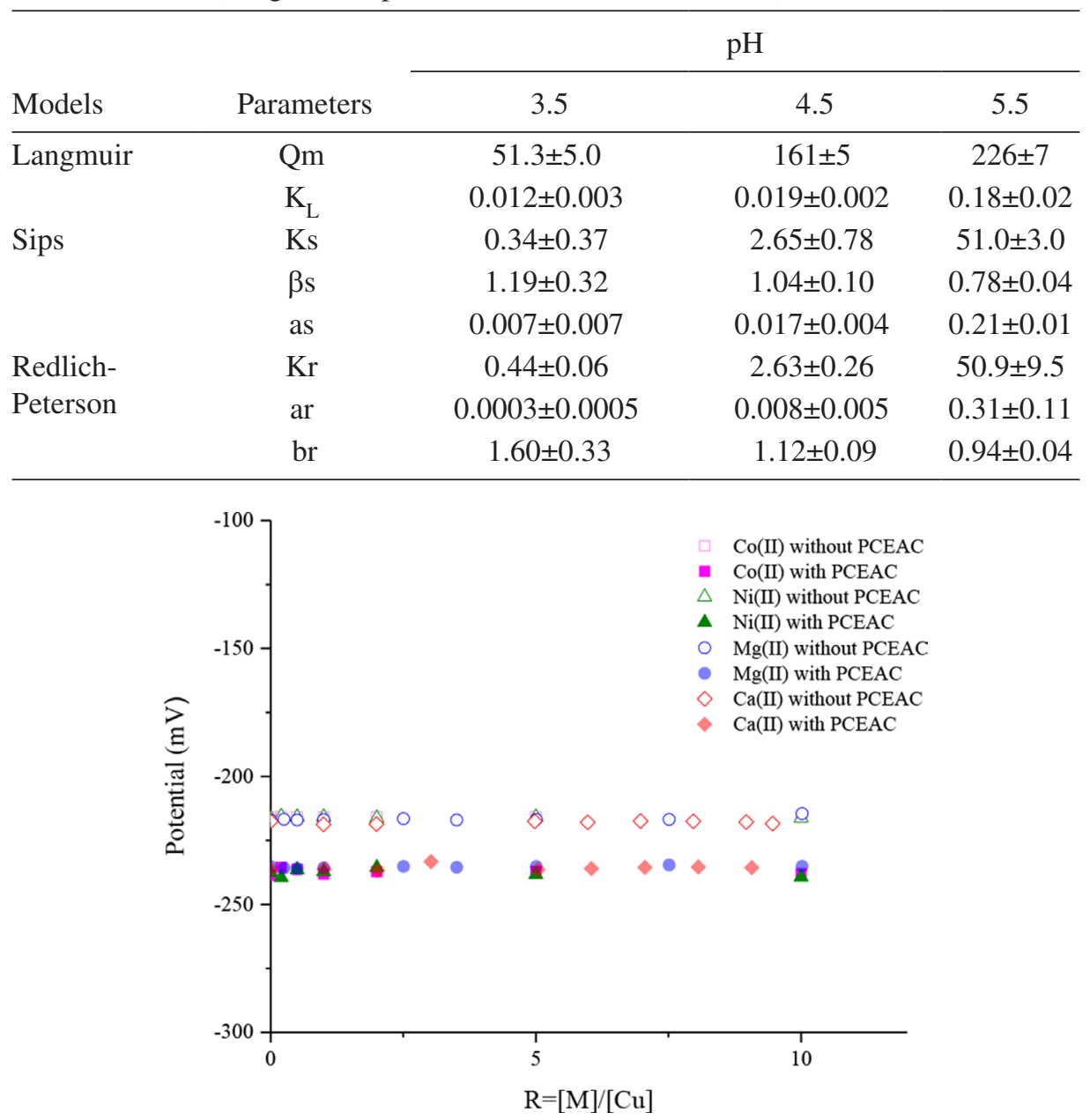

Figure 4: Selectivity of PCEAC toward Cu(II) $\left(510^{-4} \mathrm{~mol} \mathrm{~L}^{-1}\right)$ in the presence of Co(II) or $\mathrm{Ni}(\mathrm{II})$ in $0.1 \mathrm{~mol} \mathrm{~L}^{-1} \mathrm{Na}_{2} \mathrm{SO}_{4}$ at $\mathrm{pH}=5(\mathrm{R}=[$ metallic ion $] /[\mathrm{Cu}(\mathrm{II})])$. 


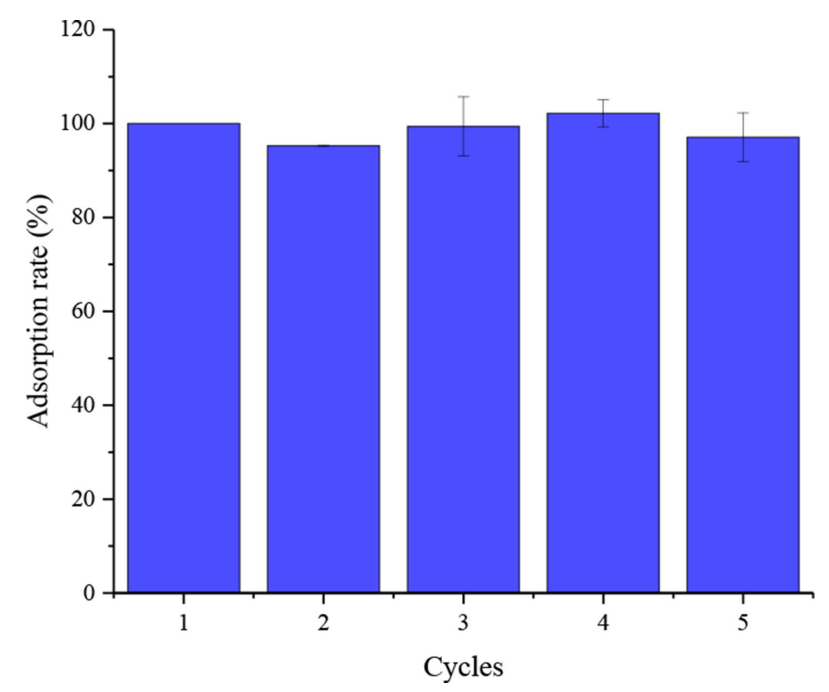

Figure 5: Copper adsorption efficiency over five cycles of sorption-desorption processes.

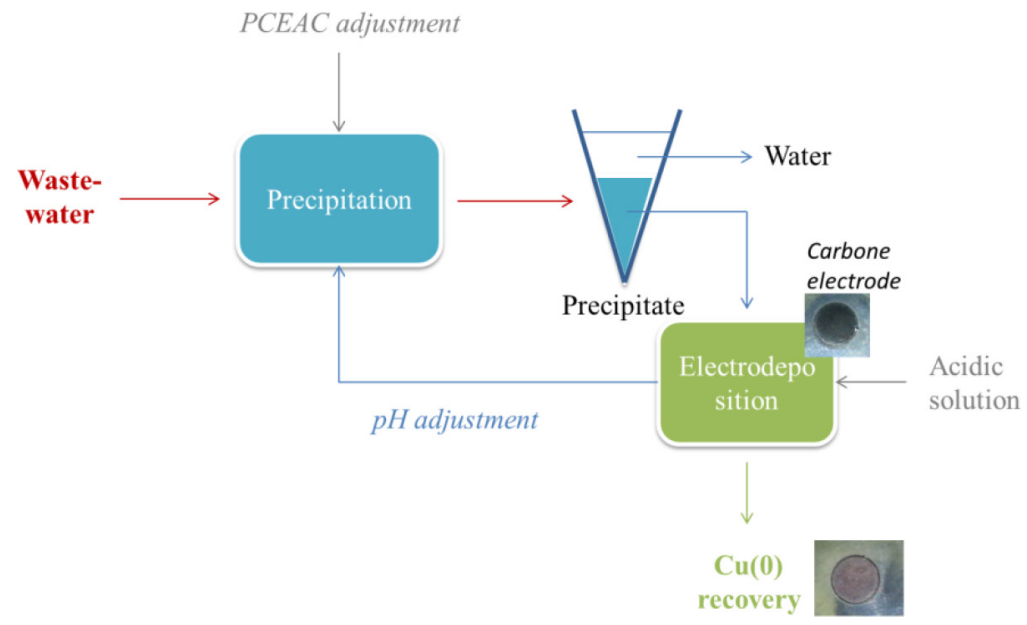

Figure 6: Two steps full process design for copper recovery using a water-soluble polycarbobetaine.

\subsection{PCEAC reusability}

The reusability of PCEAC was explored by $\mathrm{pH}$ adjustment at 2 and 4.5, respectively, for desorption and adsorption. Figure 5 confirms that the efficiency of copper adsorption was maintained over five cycles of PCEAC reuse $(99 \pm 3 \%)$ as previously reported for other polycarbobetaines [15]. 


\subsection{Full laboratory scale process for copper recovery}

The recovery of copper was engaged on PCEAC/Cu precipitate after its dissolution in acidic media $(\mathrm{pH}=2)$. Electrodeposition was operated at $-0.8 \mathrm{~V}$ on a glassy carbon electrode, and the entire recovery of copper was achieved (see pictures on Fig. 6). From these results, a two steps full laboratory scale process was designed and tested (Fig. 6).

\section{CONCLUSION}

A full process for copper recovery using a polycarbobetaine as precipitating agent was designed at laboratory for copper recovery from synthetic wastewaters. Two process units were tested: precipitation for selective copper recovery: electrodeposition in acidic media for copper recovery and polycarbobetaine regeneration. Further work will be undertaken to test the overall process with recirculation and polycarbobetaines reuse.

\section{REFERENCES}

[1] Reuter, M.A., Hudson, C., Van Schaik, A., Heiskanen, K., Meskers, C. \& Hagelüken, C., Metal recycling: opportunities, limits, infrastructure; a report of the working group on the global metal flows to the international resource panel, p. 316, 2013.

[2] Ali, S.A., Al Hamouz, O.C.S. \& Hassan, N.M., Novel cross-linked polymers having $\mathrm{pH}$-responsive amino acid residues for the removal of $\mathrm{Cu} 2+$ from aqueous solution at low concentrations. Journal of Hazardous Materials, 248-249, pp. 47-58, 2013. http://dx.doi.org/10.1016/j.jhazmat.2012.12.052

[3] Ahmaruzzaman, M., Industrial wastes as low-cost potential adsorbents for the treatment of wastewater laden with heavy metals. Advances in Colloid and Interface Science, 166, pp. 36-59, 2011. http://dx.doi.org/10.1016/j.cis.2011.04.005

[4] Kudaibergenov, S., Jaeger, W. \& Laschewsky, A., Polymeric betaines: synthesis, characterization, and application. Advances in Polymer Science, 201, pp. 157-224, 2006. http://dx.doi.org/10.1007/12_078

[5] Moreno-Villoslada, I. \& Rivas, B.L., Competition of divalent metal ions with monovalent metal ions on the adsorption on water-soluble polymers. The Journal of Physical Chemistry B, 106, pp. 9708-9711, 2002. http://dx.doi.org/10.1021/jp013345s

[6] Wang, X.-S. \& Qin, Y., Equilibrium sorption isotherms for of $\mathrm{Cu} 2+$ on rice bran. Process Biochem, 40, pp. 677-680, 2005. http://dx.doi.org/10.1016/j.procbio.2004.01.043

[7] Foo, K.Y. \& Hameed, B.H., Insights into the modeling of adsorption isotherm systems. Chemical Engineering Journal, 156, pp. 2-10, 2010. http://dx.doi.org/10.1016/j.cej.2009.09.013

[8] Didukh, A.G., Koizhaiganova, R.B., Bimendina, L.A. \& Kudaibergenov, S.E., Synthesis and characterization of novel hydrophobically modified polybetaines as pour point depressants. Journal of Applied Polymer Science, 92, pp. 1042-1048, 2004. http://dx.doi.org/10.1002/app.20075

[9] Noh, ,Sung, ,Geckeler, K.E. \& Kudaibergenov, S.E., Synthesis, characterization, and stimuli-sensitive properties of novel polycarbobetaines. Polymer, 46, pp. 2183-2190, 2005.

http://dx.doi.org/10.1016/j.polymer.2005.01.005 
[10] Didukh, A.G., Koizhaiganova, R.B., Khamitzhanova, G., Bimendina, L.A. \& Kudaibergenov, S.E., Stimuli-sensitive behaviour of novel betaine-type polyampholytes. Polymer International, 52, pp. 883-891, 2003.

http://dx.doi.org/10.1002/pi.1104

[11] Kudaibergenov, S.E., Bimendina, L.A. \& Yashkarova, M.G., Preparation and characterization of novel polymeric betaines based on aminocrotonates. Journal Macromolecular Science, Part A: Pure and Applied Chemistry, 44, pp. 899-912, 2007. http://dx.doi.org/10.1080/10601320701407995

[12] Koizhaiganova, R.B., Kudaibergenov, S.E. \& Geckeler, K.E., A novel class of betainetype polyampholytes with stimuli-responsive and complexing properties. Macromolecular Rapid Communications, 23, pp. 1041-1044, 2002.

http://dx.doi.org/10.1002/marc.200290010

[13] Cartechini, L., Miliani, C., Brunetti, B.G., Sgamellotti, A., Altavilla, C., Ciliberto, E. \& D'Acapito, F., X-ray absorption investigations of copper resinate blackening in a XV century Italian painting. Applied Physics A, 92, pp. 243-250, 2008. http://dx.doi.org/10.1007/s00339-008-4498-y

[14] Karaliota, A., Kretsi, O. \& Tzougraki, C., Synthesis and characterization of a binuclear coumarin-3-carboxylate copper(II) complex. Journal of Inorganic Biochemistry, 84, pp. 33-37, 2001. http://dx.doi.org/10.1016/S0162-0134(00)00214-2

[15] Mouton, J., Turmine, M., Van den Berghe, H. \& Coudane, J., A new water-soluble polycarbobetaine showing high selectivity toward copper. Chemical Engineering Journal, 283, pp. 1168-1175, 2016.

http://dx.doi.org/10.1016/j.cej.2015.08.058

[16] Copello, G.J., Diaz, L.E. \& Campo Dall' Orto, V., Adsorption of Cd(II) and Pb(II) onto a one step-synthesized polyampholyte: kinetics and equilibrium studies. Journal of Hazardous Materials, 217-218, pp. 374-381, 2012.

http://dx.doi.org/10.1016/j.jhazmat.2012.03.045

[17] Hadi, M., Samarghandi, M.R. \& McKay, G., Equilibrium two-parameter isotherms of acid dyes sorption by activated carbons: Study of residual errors. Chemical Engineering Journal, 160, pp. 408-416, 2010. http://dx.doi.org/10.1016/j.cej.2010.03.016

[18] Dai, Z., Wolfsberg, A., Reimus, P., Deng, H., Kwicklis, E., Ding, M., Ware, D. \& Ye, M., Identification of sorption processes and parameters for radionuclide transport in fractured rock. Journal of Hydrology, 414-415, pp. 220-230, 2012.

http://dx.doi.org/10.1016/j.jhydrol.2011.10.035

[19] Burnham, K.P., Anderson, D.R. \& Huyvaert, K.P., AIC model selection and multimodel inference in behavioral ecology: some background, observations, and comparisons. $\mathrm{Be}$ havioral Ecology Sociobiology, 65, pp. 23-35, 2010. http://dx.doi.org/10.1007/s00265-010-1029-6

[20] Papageorgiou, S.K., Katsaros, F.K., Kouvelos, E.P. \& Kanellopoulos, N.K., Prediction of binary adsorption isotherms of $\mathrm{Cu}(2+), \mathrm{Cd}(2+)$ and $\mathrm{Pb}(2+)$ on calcium alginate beads from single adsorption data. Journal of Hazardous Materials, 162, pp. 1347-1354, 2009.

http://dx.doi.org/10.1016/j.jhazmat.2008.06.022 